\title{
Nonlinearities between oil spot and futures markets: Evidence from
}

\section{intraday data}

\author{
Nicholas Apergis \\ (Department of Banking and Financial Management, University of Piraeus, Piraeus 18534, Greece)
}

\begin{abstract}
This paper builds on the literature of the relationship between oil spot and futures prices from the NYNEX market, both in their means and in their conditional volatilities, to investigate whether the association is linear or not. The novelty of this work is based on intraday data from both markets. The empirical findings indicate the presence of nonlinearities both in means and conditional volatilities. Moreover, non-linear causality estimations both in means and in volatilities reveal the presence of bi-directional causality, a fact that provides additional support to the hypothesis that both markets are driven by the same information sets.
\end{abstract}

Key words: oil spot prices; oil futures prices; non-linearity; intraday data

\section{Introduction}

The oil futures market has been characterized as one of the major factors which determine the course of the oil market. Oil futures contracts provide a shelter for hedging against risk, while they also offer great opportunities for speculation. In theoretical terms, the oil spot and the oil futures markets are associated either through the storage factor mechanism, i.e. differences in spot and futures prices are attributed to the interest foregone in storing oil inventories plus any convenience yield for holding oil inventories (Chance, 1991) or through a mechanism, according to which, differences in those prices are formed as a combination of the expected risk premium and the forecasted future spot prices (Bopp \& Sitzer, 1987). Certain studies provide evidence in favor of a long-run relationship between oil spot and futures markets (Quan, 1992; Schwartz \& Szakmary, 1994, Silvapulle \& Moosa, 1999; McAleer \& Sequeira, 2000; Chen \& Lin, 2004; Cologni \& Manera, 2008). Cunado and Perez de Gracia (2003), and Maslyuk and Smyth (2009) support the presence of a long-run relationship between the two markets, because both are driven by the same macroeconomic and microeconomic fundamentals, without ignoring short-run deviations between them, which are mainly attributed to thin trading activities, information lags, insufficient inventory levels and seasonal patterns of consumption. In addition, they report evidence that although the association is valid, it will not occur without breaks, associated to regime shifts. By contrast, alternative empirical approaches reject the presence of such a long-run relationship, a fact that is primarily attributed either to the presence of efficient markets, i.e., the acceptance of the hypothesis that the futures price is an unbiased predictor of the spot price at maturity (Dwyer \& Wallace, 1992; Crowder \& Hamed, 1993; Krehbiel \& Adkins, 1993), or to a failure to stationarity of the control variables which were included in the association under investigation, such interest rates and convenience yields (Moosa, 1996).

According to the above analysis, in terms of lead-lag relationships between the two prices, theoretical

Nicholas Apergis, Ph.D., professor, Department of Banking and Financial Management, University of Piraeus; research fields: macroeconomics, open economic macroeconomics, international finance. 
arguments pose the belief that only oil futures prices tend to cause spot prices, while the adverse causation does not hold. These beliefs are based on the argument that futures prices tend to respond to new information more rapidly than their spot counterparts. Certain reasons support the above arguments, such as lower transaction costs and easier shorting activities. Moreover, Garbade and Silber (1983) argue that it is the mechanism of price discovery, through which a competitive reference price on futures is established and which generates a subsequent spot price. According to Quan (1992), this hypothesis does not receive any statistical supports, while Schwarz and Szakmary (1994) provide evidence that oil futures contract dominate spot contracts.

Moosa and Al-Loughani (1995) also present evidence in favor of a relationship between the two markets under study. They argue that oil futures prices are mainly determined by both arbitrageurs and speculators. Their joint activities trigger developments in the futures market by taking into consideration of any diversion between the current futures price and its counterpart price which will prevail in the future. Such developments, in turn, tend to generate new developments in the spot market. By contrast, Moosa (1996) argues that in case that certain groups of arbitrageurs and speculators do not have any direct access to the futures market, then their joint activities, first, hit the spot market and, then, the futures markets. In this case, it is the spot market that leads the futures market. In a new perspective, Kawaller, et al (1988) show that both types of prices are a function of the same determinants, such as their historic prices (in both markets) plus any new information arising from the macroeconomic environment. In this setting, there exists a mutual effect between them which generates a bidirectional causality impact.

In terms of empirical testing, the majority of the above mentioned studies have investigated the linear relationship between the two markets under study. Baek and Brock (1992) argue against the linearity of such a relationship. Since then, a bulk of empirical studies reveal the presence of nonlinearities regarding this association based on the presence of non-linear trading costs, noise traders and certain micro-structure effects (Tong, 1990; Granger \& Terasvirta, 1993; Abhyankar, 1996; CHEN \& LIN, 2004; Silvapulle \& Moosa, 1999). The new empirical results reveal spurious causality regressions that ignore nonlinearities (Dicks \& Panchenko, 2006).

Pindyck (2001) argues that both spot and futures oil markets have also been showing increasing volatility over time. However, the relationship within such a volatility testing has also diagnosed the presence of nonlinearities. Bekiros and Diks (2008) provide evidence in favor of non-linearity both in means and in volatility. The presence of such nonlinearities has a substantial impact on changing the results which were found within a linear setting.

The goal of this research paper builds on the existing literature and particularly on the seminal work by Bekiros and Diks (2008) who investigate the relationship between oil spot and oil futures prices both in their means and in their conditional volatilities. The novelty of this work is based on the employment of intraday data from both markets provided by the NYNEX exchange. Section 2 describes the data used, while section 3 presents the empirical analysis along with the empirical findings and also discusses the results. Finally, section 4 offers some concluding remarks.

\section{Data}

Intraday observations (available every minute) of oil spot(s) and futures prices of West Texas Intermediate (WTI) that are listed on the NYNEX and made available from Bloomberg, spanning the period January 2000-April 2009 were obtained. This is the US WTI representative crude oil index, since it is one of the 
well-established indexes (the other is Brent crude oil traded on the Intercontinental Exchange). Three futures contracts with maturities of one month $\left(\int_{t}^{t+1}\right)$, three months $\left(\int_{t}^{t+3}\right)$ and six months $\left(\int_{t}^{t+6}\right)$ are employed. All prices are expressed in a logarithmic form. The empirical analysis finds statistical support from RATS software (version 6.1) and the EM algorithm of the GAUSS software that runs with the non-linear GARCH model.

\section{Empirical analysis}

\subsection{Unit root testing}

The null hypothesis of non-stationarity versus the alternative that the variable is stationary is tested using the standard Augmented Dickey-Fuller (ADF) statistic (Dickey \& Fuller, 1981). The results are reported without and with a trend in Table 1. The hypothesis that the log variables of spot oil prices and of the three alternative oil futures prices contain a unit root is accepted at the $1 \%$ significant level, suggesting that all the log variables under examination are $\mathrm{I}(1)$.

Table 1 Unit root tests

\begin{tabular}{|c|c|c|c|c|}
\hline \multirow{2}{*}{ Variables } & \multicolumn{2}{|c|}{ Levels } & \multicolumn{2}{c|}{ First differences } \\
\cline { 2 - 5 } & Without trend & With trend & Without trend & $-11.58(6)^{*}$ \\
\hline $\mathrm{s}$ & $-1.33(7)$ & $-1.65(7)$ & $-10.29(5)^{*}$ & $-9.12(6)^{*}$ \\
\hline $\int_{t}^{t+1}$ & $-2.13(6)$ & $-2.35(8)$ & $-8.89(5)^{*}$ & $-10.54(7)^{*}$ \\
\hline $\int_{t}^{t+3}$ & $-2.06(6)$ & $-2.32(8)$ & $-8.21(4)^{*}$ & $-10.72(7)^{*}$ \\
\hline $\int_{t}^{t+6}$ & $-2.19(7)$ & $-2.22(8)$ & $-8.68(6)^{*}$ & . \\
\hline
\end{tabular}

Notes: Figures in brackets denote the number of lags in the augmented term that ensures white-noise residuals. The optimal lag length was determined through the Akaike information criterion (AIC) and the Schwarz-Bayes information criterion (SBIC);

* indicates significant at $1 \%$.

\subsection{Cointegration testing}

Cointegration tests, based on the methodology of Johansen and Juselius (1990), are implemented for the variables of spot and futures oil prices. The tests for cointegration results are reported in Table 2. Both the eigenvalue and the trace test statistics recommend that a long-run relationship does exist between the two jointly determined variables in either case. In this manner, the employment of an error correction (EC) modeling approach is justified. The presence of cointegration is an indication that both markets are influenced by the same group of fundamentals, i.e. macroeconomic fundamentals or fundamentals associated directly with the two markets, such as trading (arbitrage) strategies or demand and supply conditions (Narayan \& Smyth, 2005; Maslyuk \& Smyth, 2009). Moreover, the presence of such a cointegrated relationship indicates the absence of market efficiency, since the predictability of each oil market can be enhanced by employing information contained in the other oil market. In such a manner, a better regulatory and monitoring environment is more desirable to improve information flows and prohibits market manipulation (Masih \& Masih, 2002; Maslyuk \& Smyth, 2009).

Finally, it is also important to display the long-run relationships. To this end, the estimates of the cointegrating relationships yield:

$$
\begin{aligned}
& \mathrm{s}=0.358+0.941 \int_{\mathrm{t}}^{\mathrm{t}+1} \\
& \text { (5.14) (61.3) } \quad \mathrm{R}-\mathrm{BAR}^{2}=0.81 \quad \mathrm{LM}=[0.44] \quad \text { RESET }=[0.85] \\
& \mathrm{S}=0.291+0.907 \int_{t}^{t+3}
\end{aligned}
$$




$$
\begin{array}{lllll}
(3.72) \quad(46.3) & \mathrm{R}_{-}-\mathrm{BAR}^{2}=0.71 & \mathrm{LM}=[0.39] & \text { RESET }=[0.72] \\
\mathrm{s}=0.049+0.804 \int_{\mathrm{t}}^{+16} & & & \\
(4.58) \quad(45.6) & \mathrm{R}_{-} \mathrm{BAR}^{2}=0.70 & \mathrm{LM}=[0.36] & \text { RESET }=[0.63]
\end{array}
$$

Figures in parentheses denote $t$-statistics, while LM and RESET tests denote the absence of serial correlation in residuals and the acceptance of the functional form of the model respectively. The reported results display that all three types of oil futures contracts have long-run information content for the behavior of spot oil prices. In other words, even in the long run, oil markets do not seem to be characterized by market efficiency.

Table 2 Cointegration tests

\begin{tabular}{|c|c|c|c|c|c|}
\hline $\mathrm{r}$ & $\mathrm{n}-\mathrm{r}$ & $\mathrm{m} . \lambda$. & $95 \%$ & $\mathrm{Tr}$ & $95 \%$ \\
\hline \multicolumn{7}{|c|}{ Spot and one-month futures oil prices (Lags=8) } \\
\hline $\mathrm{r}=0$ & $\mathrm{r}=1$ & 37.4571 & 25.8100 & 54.1683 & 35.0700 \\
\hline $\mathrm{r}<=1$ & $\mathrm{r}=2$ & 3.2664 & 6.4600 & 3.2664 & 6.4600 \\
\hline \multicolumn{7}{|c|}{ Spot and three-month futures oil prices (Lags=8) } \\
\hline $\mathrm{r}=0$ & $\mathrm{r}=1$ & 36.4652 & 25.8100 & 46.1005 & 35.0700 \\
\hline $\mathrm{r}<=1$ & $\mathrm{r}=2$ & 3.1075 & 6.4600 & 3.1075 & 6.4600 \\
\hline \multicolumn{7}{|c|}{ Spot and six-month futures oil prices (Lags=7) } \\
\hline $\mathrm{r}=0$ & $\mathrm{r}=1$ & 39.3433 & 25.8100 & 41.9280 & 35.0700 \\
\hline $\mathrm{r}<=1$ & $\mathrm{r}=2$ & 4.9460 & 6.4600 & 4.9460 & 6.4600 \\
\hline
\end{tabular}

Notes: $r=$ number of cointegrating vectors, $n-r=$ number of common trends, $m . \lambda .=$ maximum eigenvalue statistic, $\mathrm{Tr}=\mathrm{Trace}$ statistic.

\subsection{A vector error correction model (VECM)}

We next estimate a VECM and use the results to back out linearity or non-linearity of the relationship under investigation. The results (with only the statistically significant variables to be reported) yield:

(1) Spot oil prices and one-month forward futures oil prices:

$$
\Delta \mathrm{s}_{\mathrm{t}}=-0.046 \mathrm{EC}_{\mathrm{t}-1}+0.247 \Delta \mathrm{s}_{\mathrm{t}-1}+0.136 \Delta \mathrm{s}_{\mathrm{t}-2}+0.112 \Delta \mathrm{s}_{\mathrm{t}-3}+0.087 \Delta \mathrm{s}_{\mathrm{t}-6}+0.186 \Delta \mathrm{f}_{\mathrm{t}-1}
$$

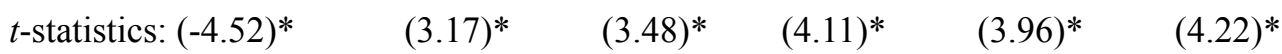

$$
\begin{aligned}
& +0.134 \Delta \mathrm{f}_{\mathrm{t}-2}+0.094 \Delta \mathrm{f}_{\mathrm{t}-4}+0.081 \Delta \mathrm{f}_{\mathrm{t}-6} \\
& (3.75)^{*} \quad(3.83)^{*} \quad(3.74)^{*} \\
& \mathrm{R}_{-\mathrm{BAR}^{2}}=0.42 \quad \mathrm{LM}=[0.21] \quad \mathrm{RESET}=[0.94] \quad \mathrm{ARCH}(8)=[0.07] \\
& \Delta \mathrm{f}_{\mathrm{t}}=-0.035 \mathrm{EC}_{\mathrm{t}-1}+0.218 \Delta \mathrm{s}_{\mathrm{t}-1}+0.147 \Delta \mathrm{s}_{\mathrm{t}-2}+0.120 \Delta \mathrm{s}_{\mathrm{t}-3}+0.062 \Delta \mathrm{s}_{\mathrm{t}-4}+0.206 \Delta \mathrm{f}_{\mathrm{t}-1}
\end{aligned}
$$

$$
\begin{aligned}
& \begin{array}{llllll}
t \text {-statistics: }(-3.86)^{*} & (3.33)^{*} & (4.03)^{*} & (3.82)^{*} & (3.52)^{*} & (4.09)^{*}
\end{array} \\
& +0.151 \Delta \mathrm{f}_{\mathrm{t}-2}+0.116 \Delta \mathrm{f}_{\mathrm{t}-3}+0.075 \Delta \mathrm{f}_{\mathrm{t}-4} \\
& (3.81)^{*} \quad(3.66)^{*} \quad(3.69)^{*}
\end{aligned}
$$

$\mathrm{R}-B A R^{2}=0.37 \quad \mathrm{LM}=[0.32] \quad \operatorname{RESET}=[0.93] \quad \mathrm{ARCH}(8)=[0.84]$

(2) Spot oil prices and three-month forward futures oil prices:

$$
\Delta \mathrm{s}_{\mathrm{t}}=-0.039 \mathrm{EC}_{\mathrm{t}-1}+0.226 \Delta \mathrm{s}_{\mathrm{t}-1}+0.117 \Delta \mathrm{s}_{\mathrm{t}-2}+0.102 \Delta \mathrm{s}_{\mathrm{t}-3}+0.074 \Delta \mathrm{s}_{\mathrm{t}-5}+0.152 \Delta \mathrm{f}_{\mathrm{t}-1}
$$

$$
\begin{array}{cccc}
t \text {-statistics: }(-3.51)^{*} & (3.28)^{*} & (3.88)^{*} & (3.84)^{*} \quad(3.48)^{*} \quad(3.35)^{*} \\
+ & 0.119 \Delta \mathrm{f}_{\mathrm{t}-2}+0.073 \Delta \mathrm{f}_{\mathrm{t}-3}+0.047 \Delta \mathrm{f}_{\mathrm{t}-5} & \\
(3.48)^{*} & (3.77)^{*} & (3.46)^{*} & \\
\mathrm{R}-\mathrm{BAR}{ }^{2}=0.37 & \mathrm{LM}=[0.13] & \mathrm{RESET}=[0.87] \quad \mathrm{ARCH}(8)=[0.11] \\
\Delta \mathrm{f}_{\mathrm{t}}=- & -0.027 \mathrm{EC}_{\mathrm{t}-1}+0.176 \Delta \mathrm{s}_{\mathrm{t}-1}+0.123 \Delta \mathrm{s}_{\mathrm{t}-2}+0.106 \Delta \mathrm{s}_{\mathrm{t}-3}+0.071 \Delta \mathrm{s}_{\mathrm{t}-4}+0.179 \Delta \mathrm{f}_{\mathrm{t}-1}
\end{array}
$$




$$
\begin{aligned}
& t \text {-statistics: }(-3.68)^{*} \quad(3.27)^{*} \quad(3.83)^{*} \quad(3.55)^{*} \quad(3.28)^{*} \quad(4.74)^{*} \\
& +0.133 \Delta \mathrm{f}_{\mathrm{t}-2}+0.095 \Delta \mathrm{f}_{\mathrm{t}-3}+0.069 \Delta \mathrm{f}_{\mathrm{t}-5} \\
& (3.73)^{*} \quad(3.29)^{*} \quad(3.44)^{*} \\
& \mathrm{R}_{-B^{2}}=0.28 \quad \mathrm{LM}=[0.35] \quad \operatorname{RESET}=[0.78] \quad \operatorname{ARCH}(8)=[0.74] \\
& \Delta \mathrm{s}_{\mathrm{t}}=-0.032 \mathrm{EC}_{\mathrm{t}-1}+0.204 \Delta \mathrm{s}_{\mathrm{t}-1}+0.125 \Delta \mathrm{s}_{\mathrm{t}-2}+0.093 \Delta \mathrm{s}_{\mathrm{t}-4}+0.071 \Delta \mathrm{s}_{\mathrm{t}-6}+0.146 \Delta \mathrm{f}_{\mathrm{t}-1} \\
& t \text {-statistics: }(-3.39)^{*} \quad(3.16)^{*} \quad(3.53)^{*} \quad(3.44)^{*} \quad(3.68)^{*} \quad(4.05)^{*} \\
& +0.106 \Delta \mathrm{f}_{\mathrm{t}-2}+0.062 \Delta \mathrm{f}_{\mathrm{t}-3}+0.045 \Delta \mathrm{f}_{\mathrm{t}-6} \\
& (3.46)^{*} \quad(3.72)^{*} \quad(3.37)^{*} \\
& \mathrm{R}-\mathrm{BAR}^{2}=0.31 \quad \mathrm{LM}=[0.16] \quad \operatorname{RESET}=[0.76] \quad \operatorname{ARCH}(7)=[0.14] \\
& \Delta \mathrm{f}_{\mathrm{t}}=-0.018 \mathrm{EC}_{\mathrm{t}-1}+0.156 \Delta \mathrm{s}_{\mathrm{t}-1}+0.116 \Delta \mathrm{s}_{\mathrm{t}-2}+0.085 \Delta \mathrm{s}_{\mathrm{t}-3}+0.064 \Delta \mathrm{s}_{\mathrm{t}-5}+0.143 \Delta \mathrm{f}_{\mathrm{t}-1} \\
& t \text {-statistics: }(-3.74)^{*} \quad(3.16)^{*} \quad(3.95)^{*} \quad(3.43)^{*} \quad(3.50)^{*} \quad(4.27)^{*} \\
& +0.119 \Delta \mathrm{f}_{\mathrm{t}-2}+0.088 \Delta \mathrm{f}_{\mathrm{t}-3}+0.063 \Delta \mathrm{f}_{\mathrm{t}-4} \\
& (3.65)^{*} \quad(3.38)^{*} \quad(3.68)^{*}
\end{aligned}
$$

Figures in brackets denote $p$-values. The coefficients of the error-correction (EC) terms exhibit a statistically significant negative value. Their signs suggest dynamic stability, where the variables move to correct any error. Diagnostics display the absence of serial correlation in residuals (LM test), the acceptance of the functional form of the model (RESET test) and the absence of ARCH effects in all three EC equations.

\subsection{Testing for non-linearity in means}

This sub-section attempts to offer any possible evidence of a non-linear relationship between oil spot and futures prices through the non-linearity test suggested by Hamilton (2001). The null hypothesis of the test supports that the true relationship between the two prices is linear, considering a non-linear model with the following form:

$$
\mathrm{s}_{\mathrm{t}}=\mathrm{a}\left(\mathrm{x}_{\mathrm{t}}\right)+\mathrm{d}^{\prime} \mathrm{z}_{\mathrm{t}}+\varepsilon_{\mathrm{t}}
$$

where $s_{t}$ is the oil spot price, $x_{t}$ is a k-dimensional vector that contains lags in oil futures prices, for which linearity is not assumed, a(.) is a function with an unknown form (Hamilton argues that this function is the outcome of a random field and to this reason he makes use of the finite-differenced Brownian motion), $z_{t}$ is a $p$-dimensional vector with lags in oil spot prices, for which linearity is assumed and $\varepsilon_{t}$ is an error term. To implement the test, $g_{i}$ is defined on the basis of the standard deviation of the $i$ th explanatory variable:

$$
g_{i}=2\left[k\left(T^{-1} \sum_{t=1}^{T}\left(\mathrm{x}_{\mathrm{it}}-\overline{\mathrm{x}_{\mathrm{i}}}\right)\right)\right]^{-1 / 2}
$$

The above statistic governs the variability of the non-linear component with respect to the $i$ th explanatory variable, $x_{i}$. If $g_{i}=0$, then $a\left(x_{t}\right)$ is linear with respect to $x_{i}$. Next, using these values for $g_{i}$, the following statistic is calculated:

$$
h_{s t}=(1 / 2)\left[\sum_{i=1}^{4} \mathrm{~g}_{\mathrm{i}}{ }^{2}\left(\mathrm{x}_{\mathrm{it}}-\mathrm{x}_{\mathrm{is}}\right)^{2}\right]^{1 / 2}
$$

and then the author builds the $(\mathrm{T} \times \mathrm{T})$ matrix, say $H$, whose row $t$ and column $s$ element is described as:

$$
\mathrm{H}\left\{\mathrm{h}_{\mathrm{st}}\right\}=1-(2 / \pi)\left[(2 / 3) \mathrm{h}_{\mathrm{st}}\left(1-\mathrm{h}_{\mathrm{st}}{ }^{2}\right)^{3 / 2} \mathrm{~h}_{\mathrm{st}}\left(1-\mathrm{h}_{\mathrm{st}}{ }^{2}\right)^{1 / 2}+\sin ^{-1}\left(\mathrm{~h}_{\mathrm{st}}\right)\right]
$$

when $0 \leq h_{s t} \leq 1$ and as zero when $h_{s t}>1$.

The non-linear model $o s_{t}$ can be also written as: 


$$
\mathrm{s}_{\mathrm{t}}=\mathrm{a}_{0}+\mathrm{a}^{\prime} \mathrm{x}_{\mathrm{t}}+\mathrm{d}^{\prime} \mathrm{z}_{\mathrm{t}}+\mathrm{u}_{\mathrm{t}}
$$

with $u_{t}=\lambda m\left(x_{t}\right)+\varepsilon_{t}$, where $\mathrm{m}($.$) is the realization of a scalar-valued Gaussian random field with mean zero, unit$ variance and covariance function given by $H\left\{h_{s t}\right\}$ and $\lambda$ is the parameter that governs the overall importance of the non-linear component. In such a setting, if $\lambda=0$, then the relationship between the two prices under study is linear.

Once the author estimated the three VECMs from above, the authors get their residuals $(\varepsilon)$, then the author calculate their corresponding squared standard error, $\sigma^{2}$ and, next, the authors calculate the projection matrix $\mathrm{M}=\mathrm{IT}-\mathrm{X}\left(\mathrm{X}^{\prime} \mathrm{X}\right)-1 \mathrm{X}^{\prime}$. We, finally, calculate the Langrange multiplier statistic for neglected non-linearity:

$$
\mathrm{v}^{2}=\left[\varepsilon^{\prime} \mathrm{H} \varepsilon-\sigma^{2} \operatorname{tr}(\mathrm{MHM})\right]^{2} /\left\{\sigma^{4}\left\{2 \operatorname{tr}\left[\mathrm{MHM}-\varepsilon^{\prime} \varepsilon / \sigma^{2} \mathrm{M} \operatorname{tr}(\mathrm{MHM})\right]^{2}\right\}\right\}
$$

According to Hamilton (2001), the above statistic has an asymptotic $x^{2}(1)$ distribution under the null hypothesis of linearity. Table 3 shows the results of the non-linearity test. They exhibit that the null hypothesis that: the relationship between spot oil prices and futures oil prices is linear is rejected.

Table 3 Nonlinearity tests

\begin{tabular}{|l|l|}
\hline Spot oil prices and one-month futures oil prices & $\mathrm{v}^{2}=15.68[0.0045]^{*}$ \\
\hline Spot oil prices and three-month futures oil prices & $\mathrm{v}^{2}=11.46[0.0027]^{*}$ \\
\hline Spot oil prices and six-month futures oil prices & $\mathrm{v}^{2}=9.71[0.0033]^{*}$ \\
\hline
\end{tabular}

Notes: Figures in brackets denote $p$-values. An asterisk indicates significance at $1 \%$.

\subsection{Testing for non-linearity in volatilities}

Over the recent years, the presence of non-linearities in the conditional variance of the bulk of assets has been extensively identified (Hagerud, 1997; Kroner \& Ng, 1998; Sheppard, 2002; Audrino \& Barone-Adesi, 2003). The presence of such non-linearities has been explained through the time-varying risk premium hypothesis. More specifically, the presence, say of negative returns, leads to an increase of their conditional volatility by more vis-à-vis to that, following the presence of positive returns. In this manner, investors require higher returns to be compensated for the higher risk they undertake, resulting in lower prices. However, this research has focused on equities and bonds but not on commodity assets, such as oil. These sub-section steps forward and with intraday data comes to fill the gap.

The author makes use of the BiLinear general auto regressive conditional heteroskedasticity (BL-GARCH) model suggested by Storti and Vitale (2003), which seems very suitable for models in which two asset markets are involved. This model is capable of capturing non-linearities in conditional variances. In particular, in order to estimate the conditional covariance matrix between the two market variables under investigation, the BL-GARCH procedure is applied to the residuals of the VECM. To serve the empirical needs of the procedure, a GARCH(1, 1) model is considered. The maximum likelihood estimates along with the associated z-statistics are reported in Table 4. All the GARCH estimates (conditional variances and conditional covariances) are statistically significant. In addition, the estimates of $\mathrm{q}_{\mathrm{ss}}(2,1), \mathrm{q}_{\mathrm{ff}}(2,1), \mathrm{q}_{\mathrm{sf}}(2,1)$ and $\mathrm{q}_{\mathrm{sf}}(1,2)$ turn out to be negative, indicating the presence of non-liniarities in the conditional variance and covariance dynamics.

\subsection{Non-linear causality in means}

Certain studies have examined the causal relationships between the two markets in order to determine any lead-lag relationship between them along with their implications. In particular, Bopp and Sitzer (1987) find that oil futures prices are good predictors for oil spot prices. In other words, oil futures prices lead to the oil spot prices. Other studies have also reached similar findings (Schwarz \& Szakmary, 1994; Chen \& Lin, 2004; Cologni \& Manera, 2008). By contrast, Kawaller, et al (1988) provide evidence in favor of bi-directional causality. These 
studies, however, use a linear framework to test for causality, while we have already showed that the association between the two markets is characterized by a non-linear setting. To this end, the authors apply the Diks and Panchenko (2006) non-linear causality $H J$ and $T 2$ tests, which are tests for conditional independence, while the null hypothesis supports non-causality.

Table 4 Estimates from the MBL-GARCH(1, 1) model

\begin{tabular}{|c|c|c|}
\hline \multicolumn{3}{|c|}{ Spot oil prices and one-month futures prices } \\
\hline & Coefficients & $z$-statistic \\
\hline $\mathrm{q}_{\mathrm{ss}}(1,1)$ & 0.057 & $3.467^{*}$ \\
\hline $\mathrm{q}_{\mathrm{ss}}(2,1)$ & -0.073 & $-8.774 *$ \\
\hline $\mathrm{q}_{\mathrm{ss}}(2,2)$ & 0.572 & $12.348^{*}$ \\
\hline $\mathrm{q}_{\mathrm{ff}}(1,1)$ & 0.051 & $6.892 *$ \\
\hline $\mathrm{q}_{\mathrm{ff}}(2,1)$ & -0.083 & $-7.993 *$ \\
\hline $\mathrm{q}_{\mathrm{ff}}(2,2)$ & 0.489 & $19.053^{*}$ \\
\hline $\mathrm{q}_{\mathrm{sf}}(1,1)$ & 0.094 & $3.073^{*}$ \\
\hline $\mathrm{q}_{\mathrm{sf}}(2,1)$ & -0.061 & $-6.891 *$ \\
\hline $\mathrm{q}_{\mathrm{sf}}(1,2)$ & -0.097 & $-9.708^{*}$ \\
\hline $\mathrm{q}_{\mathrm{sf}}(2,2)$ & 0.593 & $23.562 *$ \\
\hline \multicolumn{3}{|c|}{ Spot oil prices and three-month futures prices } \\
\hline & Coefficients & $z$-statistic \\
\hline $\mathrm{q}_{\mathrm{ss}}(1,1)$ & 0.048 & $4.127 *$ \\
\hline $\mathrm{q}_{\mathrm{ss}}(2,1)$ & -0.064 & $-7.643 *$ \\
\hline $\mathrm{q}_{\mathrm{ss}}(2,2)$ & 0.522 & $11.458^{*}$ \\
\hline $\mathrm{q}_{\mathrm{ff}}(1,1)$ & 0.068 & $6.369^{*}$ \\
\hline $\mathrm{q}_{\mathrm{ff}}(2,1)$ & -0.071 & $-8.348^{*}$ \\
\hline $\mathrm{q}_{\mathrm{ff}}(2,2)$ & 0.552 & $20.773 *$ \\
\hline $\mathrm{q}_{\mathrm{sf}}(1,1)$ & 0.078 & $3.658 *$ \\
\hline $\mathrm{q}_{\mathrm{sf}}(2,1)$ & -0.064 & $-7.812 *$ \\
\hline $\mathrm{q}_{\mathrm{sf}}(1,2)$ & -0.103 & $-9.662 *$ \\
\hline $\mathrm{q}_{\mathrm{sf}}(2,2)$ & 0.548 & $27.506^{*}$ \\
\hline \multicolumn{3}{|c|}{ Spot oil prices and six-month futures prices } \\
\hline & Coefficients & $z$-statistic \\
\hline $\mathrm{q}_{\mathrm{ss}}(1,1)$ & 0.053 & $4.545^{*}$ \\
\hline $\mathrm{q}_{\mathrm{ss}}(2,1)$ & -0.052 & $-5.448 *$ \\
\hline $\mathrm{q}_{\mathrm{ss}}(2,2)$ & 0.469 & $16.341^{*}$ \\
\hline $\mathrm{q}_{\mathrm{ff}}(1,1)$ & 0.051 & $6.228^{*}$ \\
\hline $\mathrm{q}_{\mathrm{ff}}(2,1)$ & -0.104 & $-9.376^{*}$ \\
\hline $\mathrm{q}_{\mathrm{ff}}(2,2)$ & 0.579 & $24.219 *$ \\
\hline $\mathrm{q}_{\mathrm{sf}}(1,1)$ & 0.047 & $3.793 *$ \\
\hline $\mathrm{q}_{\mathrm{sf}}(2,1)$ & -0.082 & $-6.343 *$ \\
\hline $\mathrm{q}_{\mathrm{sf}}(1,2)$ & -0.152 & $-9.220 *$ \\
\hline $\mathrm{q}_{\mathrm{sf}}(2,2)$ & 0.510 & $24.479 *$ \\
\hline
\end{tabular}

Notes: * denotes significance at $1 \%$. 
Nonlinearities between oil spot and futures markets: Evidence from intraday data

Table 5 Non-linear causality tests

\begin{tabular}{|c|c|c|}
\hline In means & & \\
\hline Lags & HJ & $\mathrm{T}_{2}$ \\
\hline \multicolumn{3}{|l|}{$\mathrm{s} \rightarrow \mathrm{f}^{\mathrm{t}+1}$} \\
\hline 1 & $11.46^{*}$ & $10.54 *$ \\
\hline 4 & $13.74 *$ & $12.62 *$ \\
\hline 8 & $9.82 *$ & $8.83 *$ \\
\hline \multicolumn{3}{|l|}{$\mathrm{f}^{\mathrm{t}+1} \rightarrow \mathrm{s}$} \\
\hline 1 & $10.55^{*}$ & $8.94 *$ \\
\hline 4 & $14.58^{*}$ & $10.77 *$ \\
\hline 8 & $10.04 *$ & $9.12 *$ \\
\hline \multicolumn{3}{|l|}{$\mathrm{s} \rightarrow \mathrm{f}^{\mathrm{t}+3}$} \\
\hline 1 & $7.93^{*}$ & $7.53 *$ \\
\hline 4 & $10.29 *$ & $10.28 *$ \\
\hline 8 & $8.57 *$ & $7.05 *$ \\
\hline \multicolumn{3}{|l|}{$\mathrm{f}^{++3} \rightarrow \mathrm{s}$} \\
\hline 1 & $13.38^{*}$ & $11.05^{*}$ \\
\hline 4 & $16.77^{*}$ & $14.56^{*}$ \\
\hline 8 & $11.29 *$ & $10.31 *$ \\
\hline \multicolumn{3}{|l|}{$\mathrm{s} \rightarrow \mathrm{f}^{\mathrm{t}+6}$} \\
\hline 1 & $5.72 *$ & $5.37 *$ \\
\hline 4 & $7.69 *$ & $7.11^{*}$ \\
\hline 8 & $6.18^{*}$ & $5.84 *$ \\
\hline \multicolumn{3}{|l|}{$\mathrm{f}^{\mathrm{t}+6} \rightarrow \mathrm{s}$} \\
\hline 1 & $5.38 *$ & $5.20 *$ \\
\hline 4 & $8.92 *$ & $6.13 *$ \\
\hline 8 & $7.12 *$ & $6.02 *$ \\
\hline \multicolumn{3}{|l|}{ In volatilities } \\
\hline \multicolumn{3}{|l|}{$\mathrm{hs} \rightarrow \mathrm{hf}^{\mathrm{t}+1}$} \\
\hline 1 & $12.33^{*}$ & $11.26^{*}$ \\
\hline 4 & $15.83^{*}$ & $13.95^{*}$ \\
\hline 8 & $13.45^{*}$ & $12.72 *$ \\
\hline \multicolumn{3}{|l|}{$\mathrm{hf}^{\mathrm{f}+1} \rightarrow \mathrm{hs}$} \\
\hline 1 & $10.73 *$ & $9.36^{*}$ \\
\hline 4 & $14.37 *$ & $11.82 *$ \\
\hline 8 & $12.94 *$ & $10.37^{*}$ \\
\hline \multicolumn{3}{|l|}{$\mathrm{hs} \rightarrow \mathrm{hf}^{\mathrm{t}+3}$} \\
\hline 1 & $9.85^{*}$ & $8.23 *$ \\
\hline 4 & $11.64 *$ & $10.81 *$ \\
\hline 8 & $9.94 *$ & $9.21 *$ \\
\hline \multicolumn{3}{|l|}{$\mathrm{hf}^{\mathrm{t}+3} \rightarrow \mathrm{hs}$} \\
\hline 1 & $10.73 *$ & $8.58 *$ \\
\hline
\end{tabular}




\begin{tabular}{|c|c|c|}
\hline 4 & $13.46^{*}$ & $9.36^{*}$ \\
\hline 8 & $9.62 *$ & $7.92 *$ \\
\hline \multicolumn{3}{|l|}{$\mathrm{hs} \rightarrow \mathrm{hf}^{\mathrm{t}+6}$} \\
\hline 1 & $6.87 *$ & $6.22 *$ \\
\hline 4 & $7.61 *$ & $6.83 *$ \\
\hline 8 & $6.99 *$ & $5.81 *$ \\
\hline \multicolumn{3}{|l|}{$\mathrm{hf}^{\mathrm{t}+6} \rightarrow \mathrm{hs}$} \\
\hline 1 & $6.12 *$ & $6.04 *$ \\
\hline 4 & $7.31 *$ & $7.23 *$ \\
\hline 8 & $8.44 *$ & $6.33^{*}$ \\
\hline
\end{tabular}

Notes: $h$ denotes the conditional volatility; * indicates significance at $1 \%$.

\subsection{Non-linear causality in volatilities}

In this sub-section, non-linear causality is investigated after controlling for the presence of conditional heteroskedasticity. The empirical results will identify not only the causal relations between the conditional variances, but also will capture the volatility persistence mechanism. The results are also reported in Table 5 and pinpoint the presence of a bi-directional causality association between the two conditional volatilities.

\section{Concluding remarks}

This paper provided evidence in favor of a non-linear relationship between spot oil prices and futures oil prices in different maturities, for the first time, with intraday data in terms in means and in conditional volatilities as well. The advantage of such estimations for the case of non-linear conditional volatilities seems extremely crucial either for hedging options or for arbitrage profitable opportunities in the oil commodity markets. The results are extremely important, in terms of information availability, for policymakers, hedge funds managers, international portfolio managers and multinational corporations for improving the decision-making process. Moreover, non-linear causality estimations both in means and in volatilities revealed the presence of bi-directional causality, a fact that provides additional support to the hypothesis that both markets are driven by the same information sets.

Future research efforts could proceed in certain directions. It could exploit the concept of non-linearity with new oil futures markets involved that depend on different types of oil, such as Chinese oil futures traded on the Shanghai Futures Exchange and the Middle East oil futures traded on the Dubai Mercantile Exchange. An alternative research effort could also employ a panel methodological approach, which could enhance the understanding of the association between oil spot prices and oil futures prices when different grades and different countries are involved.

\section{References:}

Abhyankar, A.. (1996). Does the stock index futures market tend to lead the cash? New evidence from the FT-SE 100 stock index futures market. (Working paper No. 96-01, Department of Accounting and Finance, University of Stirling).

Audrino, F. \& Barone-Adesi, G. (2003). Semiparametric multivariate GARCH models for volatility asymmetries and dynamic correlations. (Working paper, University of Southern Switzerland).

Baek, E. \& Brock, W.. (1992). A general test for non-linear Granger causality: A bivariate model. (Working paper, Iowa State University and University of Wiskonsin, Madison).

Bekiros, S. D. \& Diks, C. G. H.. (2008). The relationship between crude oil spot and futures prices: Cointegration, linear and 
non-linear causality. Energy Economics, 30, 2673-2685.

Bopp, A. E. \& Sitzer, S.. (1987). Are petroleum futures prices good predictors of cash value? The Journal of Futures Markets, 7 , 705-719.

Chance, D. M.. (1991). An introduction to options and futures. Chicago: Dryden Press.

Chen, A. S. \& Lin, J. W.. (2004). Cointegration and detectable linear and nonlinear causality: Analysis using the London metal exchange lead contract. Applied Economics, 36, 1157-1167.

Cologni, A. \& Manera, M.. (2008). Oil prices, inflation and interest rates in a structural cointegrated VAR model for the G-7 countries. Energy Economics, 30, 856-888.

Crowder, W. J. \& Hamed, A.. (1993). A cointegration test for oil futures market efficiency. Journal of Futures Market, 13, $933-941$.

Cunado, J. \& Perez de Gracia, F.. (2003). Do oil price shocks matter? Evidence for some European countries. Energy Economics, 25, $137-154$.

Dickey, D. A. \& Fuller, W. A.. (1981). Likelihood ratio statistics for autoregressive time series with a unit root. Econometrica, 49 , 1057-1072.

Diks, C. \& Panchenko, V.. (2006). A new statistic and practical guidelines for nonparametric Granger causality testing. Journal of Economic Dynamics and Control, 30, 1647-1669.

Dwyer, G. P. \& Wallace, M. S.. (1992). Cointegration and market efficiency. Journal of International Money and Finance, 11, 318-327.

Garbade, K. D. \& Silber, W. L.. (1983). Price movement and price discovery in futures and cash markets. Review of Economics and Statistics, 65, 289-297.

Granger, C. W. J. \& Terasvirta, T.. (1993). Modelling nonlinear economic relationships. Oxford: Oxford University Press.

Hagerud, G. E.. (1997). Specification tests for asymmetric GARCH. (Stocholm School of Economics, Working Paper Series in Economics and Finance, No. 163.).

Hamilton, J.. (2001). A parametric approach to flexible nonlinear inference. Econometrica, 69, 537-573.

Johansen, S. \& Juselius, C.. (1990). Maximum likelihood estimation and inference on cointegration-with applications to the demand for money. Oxford Bulletin of Economics and Statistics, 52, 169-210.

Kawaller, I. G., Koch, P. D. \& Koch, T. W.. (1988). The relationship between the S\&P 500 index and the S\&P 500 index futures prices. Economic Review, 73, 2-10, Federal Reserve Bank of Atlanta.

Krehbiel, T. \& Adkins, L. C.. (1993). Cointegration tests of the unbiased expectations hypothesis in metals markets. The Journal of Futures Markets, 13, 753-763.

Kroner, K. F. \& Ng, V. K.. (1998). Modeling symmetric comovements of asset returns. Review of Financial Studies, 11, 817-844.

Mashin, A. M. M. \& Mashin, R.. (2002). Propagative causal price transmission among international stock markets: Evidence from the pre and post globalization period. Global Finance Journal, 13, 63-91.

Maslyuk, S. \& Smyth, R.. (2009). Cointegration between oil spot and future prices of the same and different grades in the presence of structural change. Energy Policy, 37, 1687-1693.

McAleer, M. \& Sequeira, J. M.. (2004). Efficient estimation and testing of oil futures contracts in a mutual offset system. Applied Financial Economics, 14, 953-962.

Moosa, I. A.. (1996). An econometric model of price determination in the crude oil futures market. In: M. McAleer, P. Miller \& K. Leong (Eds.), Proceedings of the Econometric Society Australasian Meeting 3, Perth: University of Western Australia.

Moosa, I. A. \& Al-Loughani, N. E.. (1995). The effectiveness of arbitrage and speculation in the crude oil futures market. The Journal of Futures Market, 15, 167-186.

Narayan, P. K. \& Smyth, R.. (2005). Cointegration of stock markets between New Zealand, Australia and the G7 economies: Searching for co-movement under structural change. Australian Economic Papers, 44, 231-247.

Pindyck, R. S.. (2001). The dynamics of commodity spot and futures markets: A primer. Energy Journal, 22, 1-29.

Quan, J.. (1992). Two-step testing procedure for price discovery role of futures prices. The Journal of Futures Markets, 12, $139-149$.

Schwarz, T. V. \& Szakmary, A. C.. (1994). Price discovery in petroleum markets: Arbitrage, cointegration, and the time interval of analysis. The Journal of Futures Markets, 14, 147-167.

Sheppard, K.. (2002). Understanding the dynamics of equity covariance. (Manuscript, University of California, San Diego.)

Silvapulle, P. \& Moosa, I. A.. (1999). The relationship between spot and futures prices: Evidence from the crude oil market. Journal of Futures Markets, 19, 175-193.

Storti, G. \& Vitale, C.. (2003). Likelihood inference in BL-GARCH models. Computational Statistics, 18, 387-400.

Tong, H.. (1990). Nonlinear time series: A dynamic systems approach. Oxford: Oxford University Press. 